\title{
Review of Research on Physical Properties of Coral Sands
}

\author{
Binbin $\mathrm{Xu}^{1, \mathrm{a}}$ and Aijun Zhuge $\mathrm{C}^{2, \mathrm{~b}}$ \\ ${ }^{1}$ Tianjin Port Engineering Institute Ltd. of CCCC, Tianjin, China; Key Lab. of Geotechnical \\ Engineering of Tianjin, Tianjin, China; Key Lab. of Geotechnical Engineering, Ministry of \\ Communication, Tianjin, China \\ ${ }^{2}$ Tianjin Port Engineering Institute Ltd. of CCCC, Tianjin, China; Key Lab. of Geotechnical \\ Engineering of Tianjin, Tianjin, China; Key Lab. of Geotechnical Engineering, Ministry of \\ Communication, Tianjin, China \\ axubinbin@tpei.com.cn, ${ }^{\mathrm{b}}$ zhugeaijun@tpei.com.cn
}

\begin{abstract}
Keywords: Coral sand, Siliceous sand, Physical property, Engineering property
Abstract. The differences between coral sand and siliceous sand have been ignored until the large development of construction in coral area. In order to investigate the influence of physical property on the engineering property for coral sands, this paper reviewed the previous research literatures and summarized the basic physical properties of coral sand for reference. It is found that one of the significant properties of the coral sand is inner void, which makes the density of coral sand particles small and easy to damage under external forces.
\end{abstract}

\section{Introduction}

In geotechnical field, sand is always classified as granular materials where greater than $85 \%$ of the fine particles are with diameters at the range 0.05 to $2 \mathrm{~mm}$. However, a wide variety of properties, for example the strength or smoothness, may be attributed to the fine particles within such categorization of sands. The coral sands are derived from the dead of coral reef after a long-term geological process. It is widely distributed at the tropical sea area. In order to evaluate the suitability of site for construction, the physical properties of coral sand should be investigated in detail.

Many researches have devoted themselves on the research of physical properties of coral sands and the paper aims to list the research results for reference. In 1960, the basic proper of coral sands grasp the emphasis of engineer with the development of the first drill holes of petroleum in Arabian Gulf, and it is the first time that the calcareous sedimentary deposit is mentioned in the literature. But because there is not any engineering experience in such kind of sand, the relative research was not enriched by this opportunity. Until 1968, during the construction of Lavan oil platform, a pile with 1m diameters suddenly dropped around $15 \mathrm{~m}$ after going through a $8 \mathrm{~m}$ well-cementation ground and the much difference between coral sand and siliceous sand began to be realized.

There are mainly two categories concerning the research of coral sands: engineering-practice type and theoretical-analysis type. In the former, numerous in-site and indoor experiments are preferred to summarize the results and in the latter, indoor experiments and theoretical analysis are more used.

According to literature review, Siliceous sand can be found along rivers and coasts where grains are originally derived from the land, especially by erosive action. It is relatively easy to make uniform reconstituted samples in any case for laboratory testing. Thus, siliceous sands have generally been performed as standard sands for research purposes. The mechanical behavior of siliceous sands from different sites is generally similar, thus spatial variability is usually not a major concern.

On the other hand, coral sand deposits are derived mostly from the sedimentation of the carbonate skeletons of different varieties of marine organisms. They can be found along the coasts and the continental shelves in tropical regions where marine biological activity would have occurred in the past. Coral sand is mainly composed of calcium carbonate. High angularity and compressibility of soil skeleton are the main features of coral sands. The presence of high inter-particle voids due to the angularity of the soil grains and the presence of intra-particle voids due to hollow skeletal soil particles 
lead to relatively high void ratios. Deposits of coral sands are therefore highly susceptible to damage, even under practical levels of loading. Environmental conditions such as temperature, salinity, sunlight and water clarity also provide significant differences in their forms even for samples at the same site. Semple [1] and Coop and Airey [2] provide clear summaries for calcareous materials.

\section{Engineering Properties}

Research in Abroad. Table 1 summarizes the basic properties of typical siliceous and coral sands from the literature. From the table, higher maximum and minimum void ratios, $\mathrm{e}_{\max }$ and $\mathrm{e}_{\min }$, for coral sands are found. The high $e_{\max }$ values arise from the high angularity of most coral sands and the presence of intra-particle voids. The high compressibility of coral sands, at only moderate stress levels, is consistent with the wide void ratio range, $\left(\mathrm{e}_{\max }-\mathrm{e}_{\min }\right)$. Moreover, the yield pressure, $p_{y}$, can be calculated using Cam-clay model parameters for the soils. The $p_{y}$ values in the table are calculated based on the samples with initial relative density of $90 \%$ at $p=1 \mathrm{kPa}$. The $p_{y}$ values for coral sands are significantly lower than that for siliceous sands. Such lower $p_{y}$ values suggest that the deformation on coral sand show significant compression even at lower stress level.

Table 1 Properties and critical state parameters for various sands

\begin{tabular}{ccccccccc}
\hline Sands & $\mathrm{D}_{50}$ & $\mathrm{C}_{\mathrm{u}}$ & $\mathrm{e}_{\max }$ & $\mathrm{e}_{\min }$ & \multicolumn{3}{c}{ Cam-clay parameters } & $p_{y}$ \\
\hline Coral sands & & & & & $\lambda$ & $\kappa$ & $\mathrm{N}$ & \\
\hline Dogs Bay & 0.3 & 2.06 & 2.21 & 1.48 & 0.335 & 0.013 & 3.8 & 1.07 \\
\hline Goodwyn & 0.1 & 4.6 & 2.04 & 1.41 & 0.29 & 0.017 & 3.3 & 0.81 \\
\hline Ledge Point & 0.27 & 1.84 & 1.22 & 0.88 & 0.185 & 0.006 & 2.5 & 7.05 \\
\hline North Rankin & 0.23 & 3.75 & 1.79 & 1.22 & 0.22 & 0.014 & 2.67 & 0.86 \\
\hline Rottnest & 0.17 & 1.5 & 1.21 & 0.84 & 0.192 & 0.019 & 2.4 & 6.66 \\
\hline Quiou & 0.7 & 4.5 & 1.2 & 0.78 & 0.152 & - & 2.02 & 4.61 \\
\hline Siliceous sands & & & & & & & & \\
\hline Ham River & 0.31 & 1.55 & 0.92 & 0.59 & 0.16 & 0.013 & 2.17 & 37.2 \\
\hline Leighton & 0.12 & 1.48 & 0.84 & 0.51 & - & - & - & - \\
\hline Ottawa & 0.28 & 1.5 & 0.75 & 0.48 & 0.13 & - & 1.94 & 154 \\
\hline Sacramento & 0.21 & 1.5 & 1.03 & 0.61 & 0.2 & - & 2.5 & 16.8 \\
\hline Ticino & 0.53 & 1.6 & 0.97 & 0.53 & 0.189 & 0.02 & 2.46 & 70.2 \\
\hline Toyoura & 0.17 & 1.5 & 0.98 & 0.62 & 0.141 & 0.018 & 2.13 & 160 \\
\hline
\end{tabular}

In fact, $\mathrm{e}_{\max }$ and $\mathrm{e}_{\min }$ for coral sand are very sensitive to heterogeneities within the sample. For example, Finnie [3], Ismail [4] and Sharma [5] conducted density tests on Goodwyn coral sand and obtained 1.97, 2.32 and 2.04 for $\mathrm{e}_{\max }$ and $0.941,1.27$ and 1.41 for $\mathrm{e}_{\min }$, respectively. Such irregularity is frequently observed in the investigation of coral sands and may be explained by spatial variability. This has contributed to inconsistent information for calcareous samples and additional complexity for shallow foundation design.

Figure 1 shows grain size distributions of typical siliceous and coral sand. It can be seen that the gradation of Dogs Bay coral sand is almost equivalent to that of Ham River siliceous sand and the mean particle size is apparently larger than Toyoura siliceous sand. Goodwyn sand is relatively well graded with $30 \%$ fines content. The gradations of other sands can be distinguished using the value of uniformity coefficient, $C_{u}$ and mean particle size, $D_{50}$ in Table 2.1. The $C_{u}$ and $D_{50}$ values for coral sands show quite wide variation, while those for siliceous sand are almost identical. 


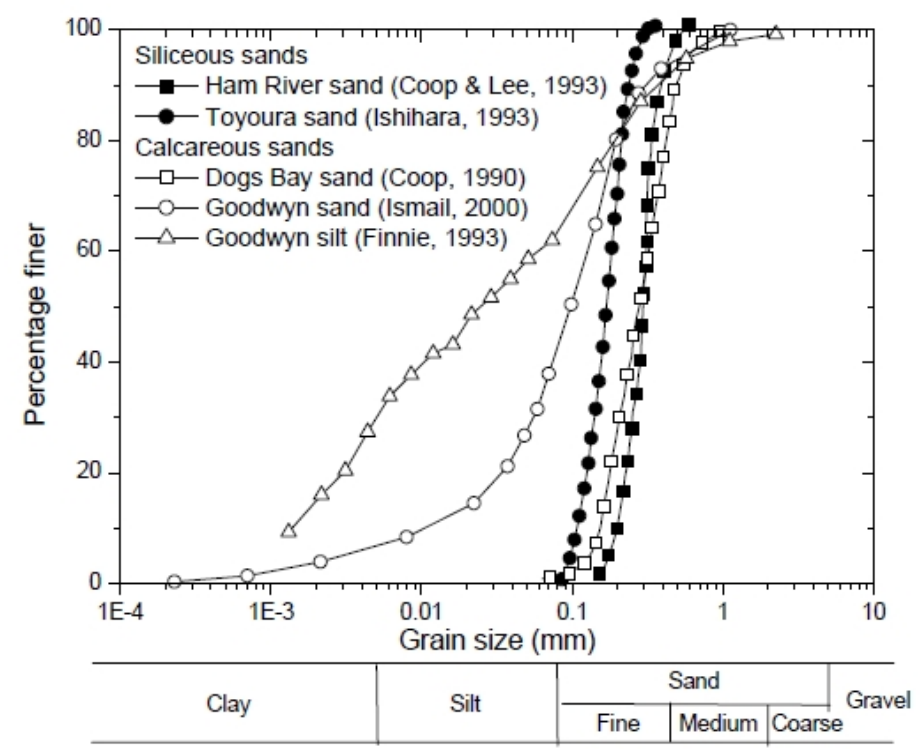

Figure 1 Grain size distribution for siliceous and coral sands

Particle Density. The average density of coral sands is between 2.73 and $2.83 \mathrm{~g} / \mathrm{m}^{3}$ in China and it is $2.80 \mathrm{~g} / \mathrm{m}^{3}$ in Japan, which is larger than the siliceous sands with average density of $2.65 \mathrm{~g} / \mathrm{m}^{3}$. Because there is easy-soluble salt at the surface of coral sand's surface and the result of density may be different using different medium. It is also found that the smaller the particle size of coral sand is, the larger the particle density is.

Specific Volume. For the coral sand, the void is composed of two parts: one is the outer-void between sand particles and the other is the inter-void inside the particles. The experimental results shows that the occupation of inter void in the whole void is about $10 \%$ and it reflects the looseness and multi-void of the coral sands. Apparently, when the inter void of the particle becomes larger, there is more possibility of particle breakage under the action of forces. The void ratio of coral sand is between 0.54 and 2.97, which is much higher than that of siliceous sands whose void ratio is around 0.4 0.9. The results shows that there is a much relationship between the void ratio and the shape of particles. When the coral sand lays in short-distance from the coral reef, the roughness of the particle is high and the void ratio is large. Table 2 presents the physical properties of coral sand around the world.

Table 2 Physical properties of coral sand in the world

\begin{tabular}{cccccc}
\hline Location & calcium carbonate $(\%)$ & $C_{u}$ & $G_{s}$ & $e_{\min }$ & $e_{\max }$ \\
\hline China & 96.7 & 1.18 & 2.73 & 0.75 & 1.26 \\
\hline Ireland & 92.5 & 1.11 & 2.72 & 1.62 & 1.98 \\
\hline India & 75 & 2.23 & 2.80 & 0.75 & 1.07 \\
\hline North-west of Austrilia & 94 & 2.43 & 2.72 & 1.22 & 1.92 \\
\hline South-east of Austrilia & 88 & 4.6 & 2.73 & 0.54 & 1.01 \\
\hline America & 92 & 3.4 & 2.82 & 1.00 & 2.97 \\
\hline
\end{tabular}

Micro-structure of Coral Sand. In order to know the inter-structure of the coral sand, the electron-microscope scanning, is used to grasp the micro-structure of the coral sands. Figure 2 shows the four typical shapes inside the coral sand. 


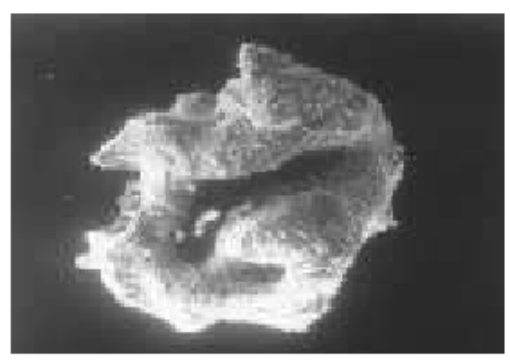

(a) Lumped shape

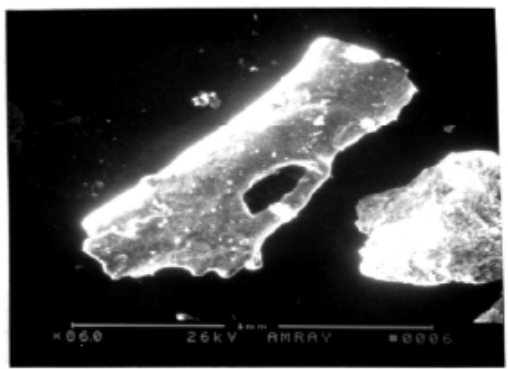

(c) slabby shape

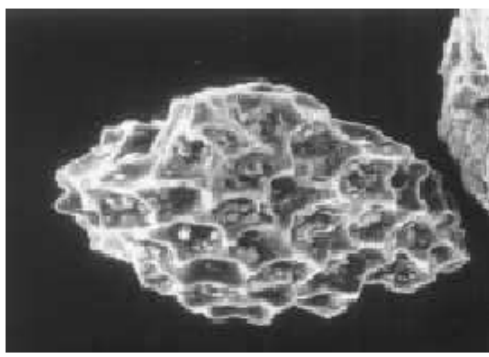

(b) spindle shape

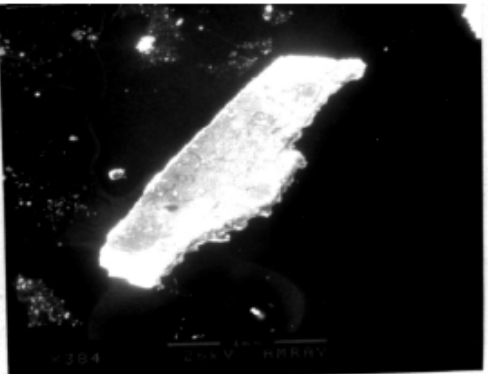

(d) tree-like shape

Figure 2 Four typical shapes of coral sands

From the scanning results, it can be seen that the structure of slabby shape is very dense and there is almost no inner void. In the tree-like shapes, usually there is inner void at the surface of the coral sands. The particles of slabby shape and spindle shapes are easy to be destroyed under external forces.

\section{Conclusions}

A brief comparison of siliceous and coral sand based on experimental results from the literature has been presented. Although both sands are categorized uniquely as sand in the geotechnical classification, they present significant differences in their behavior:

1) Coral sand is mainly composed of very weak grains, of calcium carbonate, while siliceous sand mainly contains very hard quartz grains.

2) Significant spatial variability is attributed to the coral sand in its natural state, but less significant for siliceous sand deposits.

3) One of the significant properties of the coral sand is inner void, which makes the density of coral sand particles small and easy to damage under external forces.

\section{References}

[1] R.M. Semple: Engineering for Calcareous Sediments, Vol. 2 (1988), p. 807-835.

[2] M.R. Coop and D.W. Airey: Characterisation and Engineering Properties of Natural Soils, Vol. 2, Singapore, Balkema, Rotterdam: (2003), p. 1049-1086.

[3] I.M.F. Finnie, $\mathrm{PhD}$ thesis, University of Western Australia, Australia.

[4] M.A. Ismail: $\mathrm{PhD}$ thesis, University of Western Australia, Australia.

[5] S.S.A Sharma, N. Yamamoto and M. Fahey: submitted to Canadian Geotechnical Journal, 